\title{
EL PAPEL DE LOS LAICOS EN LA PASTORAL VOCACIONAL
}

DOI: https://doi.org/10.52039/seminarios.v62i218.111

DANTE VANNINI*

INTRODUCCIÓN

Antes de comenzar estas reflexiones en el nombre del Serra Club, asociación internacional de laicos comprometidos en la pastoral vocacional, me gustaría recordar que nuestro movimiento se inspira y toma el nombre de san Junípero Serra.

Este misionero franciscano español es conocido como el «Apóstol de California», región evangelizada por él durante el siglo XVIII, donde fundó, desde San Francisco hasta Los Ángeles, las principales metrópolis que hoy existen en la costa oriental de los Estados Unidos. Por ello dicha nación le honra como uno de los padres de la patria.

Precisamente, en septiembre de 2015 asistí en Washington, junto con otros muchos miembros del Serra Club provenientes de los cinco continentes, a la canonización de san Junípero, tan deseada por Su Santidad el papa Francisco, durante su visita apostólica a América.

\section{VOCACIÓN Y MISIÓN DEL LAICO}

Para la reflexión que se me ha encomendado sobre el papel que desempeñan los laicos en la pastoral vocacional, quiero partir precisamente de la espiritualidad de san Junípero, misionero en la frontera de la evangelización. Mi trabajo profesional ha sido siempre la dirección y administración de empresas, que me ha obligado a viajar mucho, como ahora, en el Serra Club, sigo haciendo. Perdónenme, pues, si mis ideas no tienen demasiado contenido doctrinal. Les aseguro, sin embargo, que brotan del corazón y de mi experiencia personal.

San Junípero era un consagrado y un misionero: «vocación y misión» son como dos caras de la misma moneda. En la Iglesia no hay «vocación sin misión ni misión sin vocación». Una y otra -vocación y misión, misión y voca-

* Dante Vannini es el presidente del International Serra Club. 
ción- se reclaman mutuamente, y se fundamentan y verifican la una a la otra. «Dios me llama y me envía -afirmaba Juan Pablo Il y repetía Benedicto XVIcomo trabajador a su viña: me llama y envía a trabajar para la llegada de su Reino en la historia» ${ }^{1}$.

Y es ciertamente interesante, desde el punto de vista de la formación de los laicos, tomar conciencia no solo del estrecho vínculo entre vocación y misión, sino de la personalización de esta doble y única «identidad» en la vida del cristiano: la vocación es misión personal.

\section{PAPEL DEL LAICO EN LA PASTORAL VOCACIONAL}

La intuición del Concilio Vaticano II de que toda la comunidad cristiana tiene el deber de fomentar las vocaciones ${ }^{2}$, encuentra una clara traducción en la responsabilización de los laicos en este servicio eclesial tan urgente y esencial para la Iglesia: «Todos debemos sentir la responsabilidad de favorecer el surgimiento y la maduración de vocaciones especificamente misioneras, ya sacerdotales y religiosas, ya laicales $»^{3}$. ¿Cómo pueden los laicos realizar este servicio de animadores vocacionales?

El laico debe, sobre todo, comprometerse a descubrir su vocación personal y su misión, escuchando con prontitud y disponibilidad la Palabra de Dios y de la Iglesia. Debe rezar, frecuentar los sacramentos, meditar la Palabra de Dios y poner al servicio de la propia fe, en las diversas situaciones sociales e históricas en las que está inserto, los dones y talentos recibidos. Un itinerario así, de formación de los laicos, es por sí mismo un verdadero y auténtico itinerario vocacional.

El testimonio coherente de la propia y específica vocación y misión debe lograr todo esto en el laico: "Ya en el plano del ser, antes todavía que en el obrar, los cristianos son sarmientos de la única vid fecunda que es Cristo... En el plano del ser: no significa solo mediante la vida de gracia y santidad... sino que significa también el estado de vida que caracteriza a... los fieles laicos ${ }^{4}$.

Así pues, el laico, mediante el testimonio de la propia fe en el mundo concreto en el que vive, debe ser un «llamante», y debe, en este sentido, tomar conciencia del importantísimo papel que puede desempeñar en la pastoral vocacional.

Durante estos años los laicos han comprendido, en medida creciente, que con el bautismo entran a formar parte de una gran familia en cuya vida deben

1. Juan Pablo II, exhortación apostólica Christifideles laici (1988), 58.

2. Concilio Vaticano II, Decreto Optatam totius, 2.

3. Juan Pablo II, Christifideles laici, 35.

4. Ibid., 55. 
participar de manera responsable con la reflexión y con el compromiso concreto. Desde el concilio Vaticano II la presencia de los laicos en la vida de las comunidades eclesiales ha ido aumentando cada vez más: en la catequesis, en los consejos pastorales, en la liturgia.

Aquí también pueden surgir algunos problemas. Por ejemplo, el compromiso pastoral de los laicos no será positivo si va acompañado de una tendencia a huir de sus responsabilidades temporales, a menudo complejas y difíciles, o si se reduce a una rutinaria "prestación de servicios», sin esfuerzo de reflexión ni creatividad. La presencia de los laicos no será positiva si no nace del deseo de reconocer el gran valor de esta vocación original, sino que responda simplemente a una necesidad de colaborar. Ciertamente, no se trata de que los laicos participen en la vida de la Iglesia solo por el hecho de que escasean las vocaciones de sacerdotes y de religiosos.

Por todo esto, al laico, animador vocacional, lo podríamos definir -tal como propone una acertada definición que he encontrado «pescando» cosas buenas en «la red»- «como un testigo y un compañero de camino para los llamados, y no como un maestro solitario. Respeta y valora siempre la real condición humana, 'humaniza' -por así decirlo- el planteamiento vocacional, sabiendo que otros acentuarán su 'divinización'. Ha de tener un fuerte sentido del vínculo que une cada vocación con otras formas o estados de vida. Se da cuenta, mejor que otros, de que la experiencia humana no es un absoluto definitivo, sino que es sobre todo un camino que a menudo exige comenzar de nuevo; el amor perfecto siempre es una meta. Tiene viva conciencia de que, sin los sacramentos, sin la eucaristía, sin la Iglesia en su conjunto, sin el don de los ministros ordenados, ningún camino vocacional puede mantenerse $»^{5}$.

La «participación» de los laicos en la pastoral vocacional no es, por consiguiente, algo cuantitativo, sino -como precisa Mons. Marcello Semeraro, obispo de Albano- «modal», en el sentido de que, todo aquel que desea colaborar en la misión de la Iglesia entera, ha de ser consciente de que «lo decisivo no son las diversas tareas que el laico pueda o deba hacer en la pastoral o la animación vocacional promovida por un presbítero o un religioso, sino que aporte un estilo diferente, un estilo laical que debe caracterizar su ministerio según su específico modo de vida en la Iglesia. La fidelidad de los laicos a su ser laicos los hace conscientes de actuar, como dice el Concilio, como buscadores del Reino comprometidos en las realidades temporales y ordenándolas según Dios» ${ }^{6}$.

5. P. Scabini, I laici, «soggetti» della missione ecclesiale e dell'animazione vocazionale: Vocazioni VI (marzo-aprile 1989) 13-16.

6. Intervención del Card. José Saravia Martins en el XII Congreso nacional de Serra Italia, Roma 2016. 


\section{El CARISMA DEL SERRA CLUB}

En este contexto y con estas ideas que, sencilla y modestamente, acabo de exponer, se inserta y comprende el carisma del Serra Club que ahora trataré de presentar en síntesis.

El Serra es un Service Club, es decir, una asociación de servicio. Fue fundado en Seattle, en la costa occidental de Estados Unidos, en los años treinta del siglo pasado. De acuerdo con sus estatutos, tiene entre sus objetivos los siguientes: a) Favorecer y sostener las vocaciones al sacerdocio ministerial en la Iglesia católica, así como una particular vocación al servicio y sostenimiento de los sacerdotes en su sagrado ministerio. b) Fomentar y valorar las vocaciones a la vida consagrada en la Iglesia católica. c) Ayudar a los miembros del Club a reconocer y responder, cada uno en su propia vida, a la llamada de Dios a la santidad en Jesucristo por medio del Espíritu Santo.

Nuestro movimiento se difundió rápidamente por todo el mundo y llegó a Génova el año 1959. Allí fue acogido con entusiasmo por el Cardenal Siri, quien, tras conocer a los miembros genoveses del Club, apreció mucho el hecho de que había surgido un movimiento más dado a actuar que a hablar, que dentro de este movimiento la laicidad destacara como un valor fundamental y que se dirigiese sobre todo a personas (empresarios, profesionales, profesores, dirigentes...) capaces de sensibilizar a ciertos ámbitos con frecuencia indiferentes a las propuestas de la fe católica, pero muy necesarios e importantes para mantener en vigor los valores cristianos dentro del tejido vivo de las sociedades modernas, laicistas y materialistas.

Hoy día, el Serra Club quiere permanecer fiel a sus principios inspiradores, adecuando el lenguaje y sus modos de acción a los tiempos cambiantes. Así, el Serra pretende llevar a cabo la doble misión que, fundamentalmente, se le pide a cada miembro. Por un lado, fomentar una opinión pública, una cultura vocacional, un ambiente social que no obstaculice, sino que incentive la opción de quienes deciden consagrar su vida al Señor, favoreciendo así el nacimiento de vocaciones. Por otro lado, crear una red que sostenga estas vocaciones mediante acciones concretas de solidaridad, de amistad, de apoyo moral, que se traduzcan en ayuda de cualquier tipo, según las necesidades que vayan surgiendo, y todo ello sin ostentación, en la normalidad de nuestra vida de cotidiana.

Todos nos sentimos humildemente dispuestos al activo y generoso servicio que se nos pide, como laicos autónomos y organizados con autonomía, pero en plena comunión y armonía con los obispos y los rectores de los seminarios. Ellos son los puntos de referencia exclusivos para cualquier iniciativa que comprometa a quienes caminan por el difícil sendero que, a través de la compleja formación y el continuo discernimiento, los lleva a vivir totalmente al servicio del Señor. 
Así pues, insisto, aspiramos a ser «llamantes», personas prácticas y directas que dan testimonio, con su conducta y modo de vida, de la especial atención y cuidado a los consagrados y a aquellos que se preparan para serlo, manifestándoles nuestra amistad y cercanía.

Me gusta pensar que todos nuestros clubes Serra puedan ser, para los seminaristas, los religiosos, las religiosas y los sacerdotes, lo que para Jesús era la casa de Lázaro en Betania: un lugar donde estar a gusto en amistad fraterna. Desde esta perspectiva, queremos permanecer cerca de los consagrados, ya sean ancianos, ya sean personas con dificultades, que a menudo se encuentran solos y quizás abandonados, y poner a su servicio, gratuitamente y sin segundas intenciones, las habilidades profesionales y los talentos de que disponen los miembros de nuestros clubes Serra.

Así pues, el modo como el Serra Club realiza su actividad para el cuidado de las vocaciones pretende ser original y particular. No se trata solo de rezar por las vocaciones, sino de actuar para favorecer que nazcan y para cuidar su crecimiento mediante iniciativas y eventos que, desde la afirmación rigurosa de los principios fundamentales de nuestra fe católica, impliquen al mundo laico, incluso laicista, en el terreno de aquellos valores que se comparten, como los de la promoción social y la solidaridad, con el fin de mostrar a todos lo hermoso y positivo que es para el mundo entero que hombres y mujeres de toda condición y de todo origen étnico, geográfico y cultural se consagren por completo al Señor.

Que el Señor bendiga nuestros buenos propósitos y que María, madre de las vocaciones, ruegue por nosotros. 